\title{
A Monosynaptic GABAergic Input from the Inferior Colliculus to the Medial Geniculate Body in Rat
}

\author{
Daniel Peruzzi, ${ }^{1}$ Edward Bartlett, ${ }^{2}$, Philip H. Smith, ${ }^{2}$ and Douglas L. Oliver ${ }^{1}$ \\ ${ }^{1}$ Department of Anatomy, University of Connecticut Health Center, Farmington, Connecticut, 06030-3405, and \\ ${ }^{2}$ Department of Anatomy and the Neuroscience Training Program, University of Wisconsin, Madison, Wisconsin, 53706
}

The goal was to investigate possible monosynaptic GABAergic projections from the inferior colliculus (IC) to thalamocortical neurons of the medial geniculate body (MGB) in the rat. Although there is little evidence for such a projection in other sensory thalamic nuclei, a GABAergic, ascending auditory projection was reported recently in the cat. In the present study, immunohistochemical and tract-tracing methods were used to identify neurons in the IC that contain GABA and project to the MGB. GABA-positive projection neurons were most numerous in the central nucleus and less so in the dorsal and lateral cortex. They were rare in the lateral tegmental system and brachium of the IC. The dorsal nucleus of the lateral lemniscus also contained GABA-positive projection neurons. In brain slices, stimulation of the brachium produced monosynaptic inhibitory postsynaptic potentials in morphologically identified thalamocortical relay neurons. The inhibitory potentials cannot originate locally, because they persisted when ionotropic glutamatergic transmission was blocked. Typically, brachium stimulation elicited a $\mathrm{GABA}_{\mathrm{A}}$-mediated inhibitory potential followed by an excitatory potential and a longer latency $\mathrm{GABA}_{\mathrm{B}^{-}}$ mediated inhibitory potential.

We conclude that the GABA-containing neurons of the IC make short-latency, monosynaptic inputs to the thalamocortical projection neurons in the MGB. Such inputs may distinguish the main auditory pathway from indirect or tegmental auditory pathways as well as from other sensory systems. Monosynaptic inhibitory inputs to the medial geniculate may be important for the regulation of firing patterns in thalamocortical neurons.

Key words: auditory pathway; retrograde tracing; brain slice preparation; immunohistochemistry; thalamus; midbrain; reticular formation; dorsal nucleus of the lateral lemniscus
Recently, a novel and strong GABA-positive input from the inferior colliculus (IC) has been demonstrated in the cat medial geniculate body (MGB) (Winer et al., 1996). Thus, thalamocortical neurons in the MGB may receive monosynaptic, GABA-mediated inputs from the brainstem, in contrast to the neurons of other sensory thalamic nuclei. In most thalamic nuclei, inhibitory inputs come from local interneurons or intrathalamic neurons (for review, see Sherman and Koch, 1986; Steriade and Llinas, 1988). For example, in the lateral geniculate body, ascending inputs can excite directly the interneurons, which in turn inhibit thalamocortical neurons (Hirsch and Burnod, 1987; Lindstrom and Wrobel, 1990; Soltesz and Crunelli, 1992; Pape and McCormick, 1995). Such a scenario is less likely in the rat MGB. There are few local GABAergic interneurons, yet many GABA-positive axonal boutons are present (Winer and Larue, 1988, 1996). This suggests that inhibitory influences arise outside the MGB. Our goal in this study was to identify and characterize one such inhibitory input in the rat.

To test whether thalamocortical neurons of the MGB receive monosynaptic GABAergic input from the lower brainstem, we used both anatomical and electrophysiological approaches. To show that some neurons from the IC contain GABA and project

Received Jan. 21, 1997; revised Feb. 28, 1997; accepted March 6, 1997.

This research was supported by National Institutes of Health Grants R01DC00189 (D.L.O.) and R01-DC01999 (P.H.S.). We thank Gretchen Beckius, Debbie Bishop, JoAnne Ekleberry, Joan Meister, and Inge Siggelkow for their excellent technical assistance.

Correspondence should be addressed to Dr. Douglas L. Oliver, Department of Anatomy, University of Connecticut Health Center, Farmington, CT 06030-3405.

Copyright (C) 1997 Society for Neuroscience $0270-6474 / 97 / 173766-12 \$ 05.00 / 0$ to the $\mathrm{MGB}$, we injected retrograde tracer in the MGB and immunostained the IC with antisera to GABA. To show that IPSPs come from the IC, we shocked the ascending pathway to the MGB in a brain slice preparation and recorded intracellular potentials in thalamocortical neurons. We used receptor antagonists to test whether GABA is responsible for the IPSPs. Furthermore, we applied blockers of glutamatergic transmission to prevent the local excitation of inhibitory interneurons. The present results suggest that the IC is a source of short latency, monosynaptic IPSPs in the rat MGB.

\section{MATERIALS AND METHODS}

Survival surgery and immunohistochemistry. To identify GABA-positive IC neurons that project to the MGB, survival surgery was performed on seven 8-12-week-old Long-Evans hooded rats. The surgical procedures were approved by the University of Connecticut Health Center animal care committee. Rats were anesthetized with an intramuscular injection of ketamine $(97.5 \mathrm{mg} / \mathrm{ml})$ and xylaxine $(2.43 \mathrm{mg} / \mathrm{ml}, 0.1 \mathrm{ml}$ of mixture per $100 \mathrm{gm}$ of body weight). The lateral superior colliculus, brachium of the IC (BIC), and MGB were surgically exposed by aspiration of the overlying cortex. Red tetramethylrhodamine-isothiocyanate (TRITC) latex microspheres (Lumafluor, Naples, FL) were pressure injected by Picospritzer (General Valve, Fairfield, NJ) into the MGB, both caudally, where the MGB is not covered by the optic tract, and rostrally, where the optic tract lies superficial to the MGB. Injection depths were $0.5,1.0$, and sometimes $1.5 \mathrm{~mm}$. The total volume of red latex microspheres injected into the MGB per animal ranged from $\sim 1.2$ to $2 \mu \mathrm{l}$.

Immunostaining for GABA-positive immunoreactivity was performed after retrograde transport and fixation of the tissue. After surviving for $5 \mathrm{~d}$, the animals were anesthetized as described above and perfused through the heart with a washout solution $(2 \%$ sucrose, $0.05 \%$ lidocaine, $0.004 \%$ calcium chloride in $0.1 \mathrm{M}$ phosphate buffer, $\mathrm{pH} 7.3$, at $37^{\circ} \mathrm{C}$ ), followed by fixative ( $4 \%$ paraformaldehyde, $0.2 \%$ glutaraldehyde, $0.004 \%$ calcium chloride in $0.1 \mathrm{M}$ phosphate buffer, $\mathrm{pH} 7.5,37^{\circ} \mathrm{C}$ ). After the brain 
was removed and post-fixed for several days, 50- $\mu$ m-thick transverse slices were cut through the brainstem (containing the IC) and thalamus (containing the MGB) on a vibratome and collected in $0.1 \mathrm{M}$ phosphate buffer. Every other diencephalon slice was mounted with a $2.5 \%$ solution of DABCO (1,4-diazobicyclo-[2.2.2]-octane in a 9:1 mixture of glycerin/ phosphate buffered saline, $\mathrm{pH} 8.6$ ) on slides to view the fluorescent beads in the injection site of the MGB. The remaining sections were Nisslstained with thionin to reveal cytoarchitectural boundaries. In the mesencephalon, every sixth slice was Nissl-stained, and the remaining sections were processed for GABA-positive immunoreactivity. All rinses and solutions used $0.1 \mathrm{M}$ phosphate buffer. Sections were incubated for $2 \mathrm{hr}$ in a "blocker" solution of 1:10 normal horse serum, 1:1000 Triton X-100 (Sigma, St. Louis, MO), and then overnight in 1:2000 monoclonal mouse anti-GABA primary antibody (Sigma) at $4^{\circ} \mathrm{C}$ in blocker solution. Sections were rinsed and incubated for $2 \mathrm{hr}$ in the blocker solution; then they were incubated overnight in 1:200 donkey anti-mouse secondary antibody (Jackson, West Grove, PA) labeled with fluorescein-isothiocyanate (FITC). Finally, sections were rinsed three times for $10 \mathrm{~min}$ and mounted in DABCO.

Analysis. Analysis was performed on four of the seven animals, in which the best retrograde transport and immunohistochemistry were obtained. All material was viewed on a Zeiss Axioskop equipped for fluorescence with filters for FITC and TRITC and interfaced with a CCD camera (Dage-72, Michigan City, MI), stepping motors, camera lucida, frame grabber (Coreco, Saint-Laurent, Quebec, Canada), and a personal computer. Custom software (Center for Neurological Science, Farmington, CT) was used to capture and integrate the fluorescent image from the camera to a personal computer. Neurolucida (Microbrightfield, Colchester, VT) was then used to plot the data.

To analyze the injection sites, adjacent sections with injection site and cytoarchitectural information were superimposed. The section outline and microsphere injection site were collected with the video system under epi-fluorescent illumination. The adjacent Nissl section and its cytoarchitectural boundaries were entered into the computer with the camera lucida and superimposed on the data from the fluorescent section. The Nissl sections were expanded by a factor of 1.05-1.15 to compensate for histological shrinkage.

To analyze the labeling in the IC, both fluorescent and Nissl sections were examined. Cells with GABA-positive immunoreactivity exhibited FITC (green) fluorescence. Cells containing microspheres transported from the MGB showed TRITC (red) fluorescence. Cells containing FITC, TRITC, or both signals were plotted with a water-immersion $25 \times$, 0.8 NA objective. Because the antibodies for GABA-positive immunoreactivity only penetrated $\sim 10 \mu \mathrm{m}$, cells were only counted to this depth from the top of the section. The strategy was to focus on the top layer of the section that contained immunostained GABA-positive neurons and to restrict the counting of retrogradely labeled cell bodies to this layer. The resulting plots were overlaid onto plots of the adjacent, Nissl-stained sections that showed subdivisions based on cytoarchitecture. The ratio of neurons that project to the injection site and display GABA-positive immunoreactivity was calculated by dividing the number of doublelabeled neurons by the sum of double-labeled neurons and those with only microspheres. Statistical comparisons were made with an ANOVA and the Student's $t$ test, $p=0.05$.

Intracellular recording and staining. The methods described here for sharp electrode intracellular recording are similar to those described in a previous paper (Smith, 1992). For all slice experiments, 3-6 week-old Long-Evans hooded rats were used. Rats were given an anesthetic overdose of either $0.5 \mathrm{ml}$ of sodium pentobarbital $(10 \mathrm{mg} / \mathrm{ml}$, i. p. $)$ or $1.2-1.5 \mathrm{ml}$ of chloral hydrate $(70 \mathrm{mg} / \mathrm{ml}, \mathrm{i}$. p. $)$. When areflexive, rats were perfused transcardially with chilled, oxygenated sucrose saline (described below) and decapitated, and the brain exposed dorsally. Two coronal cuts were made halfway through the rostrocaudal extent of the cerebellum and halfway through the rostrocaudal extent of the cerebral cortex, and the block of tissue between these cuts was removed. For slices in the horizontal plane, the block was glued ventral side down and submerged with oxygenated saline, and $400 \mu \mathrm{m}$ slices were taken with a vibratome through the MGB. For sagittal slices, an additional midsagittal scalpel cut was made in the block, one of the halved blocks was glued midsagittal side down, and $400 \mu \mathrm{m}$ sections were taken through the MGB. To preserve the BIC and more lateral areas of the MGB in the same slice, we sometime angled the midsagittal cut with respect to the midline, such that the caudal aspect of the MGB in the slice was $\sim 500 \mu \mathrm{m}$ more medial than the rostral aspect. Sections containing the MGB were placed in a holding chamber containing either normal, oxygenated artificial CSF (ACSF), or a 50:50 mixture of oxygenated sucrose/normal ACSF at room temperature. After equilibrating in the holding chamber for at least $15 \mathrm{~min}$, one slice was transferred to the recording chamber, placed between two sets of nylon mesh, and perfused with normal, oxygenated ACSF that contained the following (in $\mathrm{mM}$ ): $\mathrm{NaCl} 124 ; \mathrm{KCl} 5 ; \mathrm{KH}_{2} \mathrm{PO}_{4} 1.2 ; \mathrm{CaCl}_{2} 2.4$; $\mathrm{MgSO}_{4}$ 1.3; $\mathrm{NaHCO}_{3} 26$; and glucose 10. The sucrose ACSF contained sucrose instead of $\mathrm{NaCl}$ (Aghajanian and Rasmussen, 1989).

Stimulating electrodes were used to activate the BIC. A stimulating electrode was situated caudal to the MGB in the BIC to drive the inputs from the IC. We have used both concentric and bipolar stimulating electrodes. To stimulate as many geniculate inputs as possible, the tip separation of the bipolar electrodes was often rather large $(>500 \mu \mathrm{m})$. Such bipolar electrodes were placed farther from the MGB to minimize antidromic activation through current spread. If a direct spike was observed, the polarity of the stimulating electrode was switched or the electrode was moved.

Intracellular recordings of responses to injected current and evoked postsynaptic potentials were made with glass microelectrodes of 80-200 $\mathrm{M} \Omega$ resistance when filled with a solution of $2 \mathrm{M}$ potassium acetate and $2 \%$ Neurobiotin (Vector, Burlingame, CA). Intracellular current and voltage records were digitized with custom software (ICEPAC, L. Haberly, University of Wisconsin). A neuron's membrane potential was calculated by subtracting the recorded intracellular voltage from the extracellular DC potential just after coming out of the cell. The input resistance of the cell was taken to be the slope of the linear portion of the current-voltage plot near the cell's resting potential. Voltage was measured for $50 \mathrm{msec}$ during the last $100 \mathrm{msec}$ of 200 or $300 \mathrm{msec}$ current pulses. The high impedance of the electrodes and a number of voltagedependent conductances in MGB neurons made the voltage deflections caused by large current injections unreliable for calculating the cell's input resistance. Bicuculline methiodide, 2-hydroxysaclofen, DL-2amino-5-phosphonovaleric acid (APV), 6,7-dinitroquinoxaline (DNQX) (all obtained from Research Biochemicals International, Natick, MA) and CGP35348 (Ciba-Geigy, West Caldwell, NJ) were all mixed with ACSF to the stated concentrations on the day of the experiment and were bath-applied. During recording, Neurobiotin was injected into the recorded cell with a $0.3-0.5 \mathrm{nA}$ current for 2-10 $\mathrm{min}$.

After the experiment, the slice was carefully removed from the recording chamber and fixed in fresh $4 \%$ paraformaldehyde. The slice was then cryoprotected by passage through a series of glycerol-sucrose solutions, and $60 \mu \mathrm{m}$ frozen sections were cut on a freezing microtome and collected in $0.1 \mathrm{M}$ phosphate buffer, $\mathrm{pH}$ 7.4. The sections then underwent histochemistry for the avidin-biotin-HRP complex (ABC Kit, Vector Labs). The following day, the sections were rinsed in phosphate buffer and the HRP reacted using the DAB-nickel/cobalt intensification method, mounted, counterstained with cresyl violet, and coverslipped.

Drawings of injected cells were made using a camera lucida attached to a Zeiss microscope. The location of the cell body relative to the divisions of the rat MGB was determined using the atlas of Paxinos and Watson (1986) and the cytoarchitectural study of the rat MGB by Clerici and Coleman (1990).

\section{RESULTS}

\section{Anatomy of GABA-positive tectothalamic projections Microsphere injection sites}

In all four cases, the injection sites were similar to each other and were largely contained within the MGB. The case (96-6) with the smallest injection site and that (95-84) with the largest are illustrated in Figure 1. The diagrams show transverse sections through the caudal diencephalon of these two animals. Both injection sites include the dorsal and ventral divisions of the MGB. In addition, the injection sites extend into the peripeduncular nucleus just ventral to the MGB (95-84, $A-D ; 96-6, A$ and $D)$. There were no differences in the resulting pattern of midbrain labeling (Figs. 3, 4) between 96-6 and 95-84 that were attributable to the greater spread of beads ventrally in 95-84.

\section{Midbrain labeling}

The labels for retrograde transport and GABA-positive immunoreactivity were distinguished easily. "GABA-positive" immunoreactivity was indicated by FITC label with a uniform green appear- 

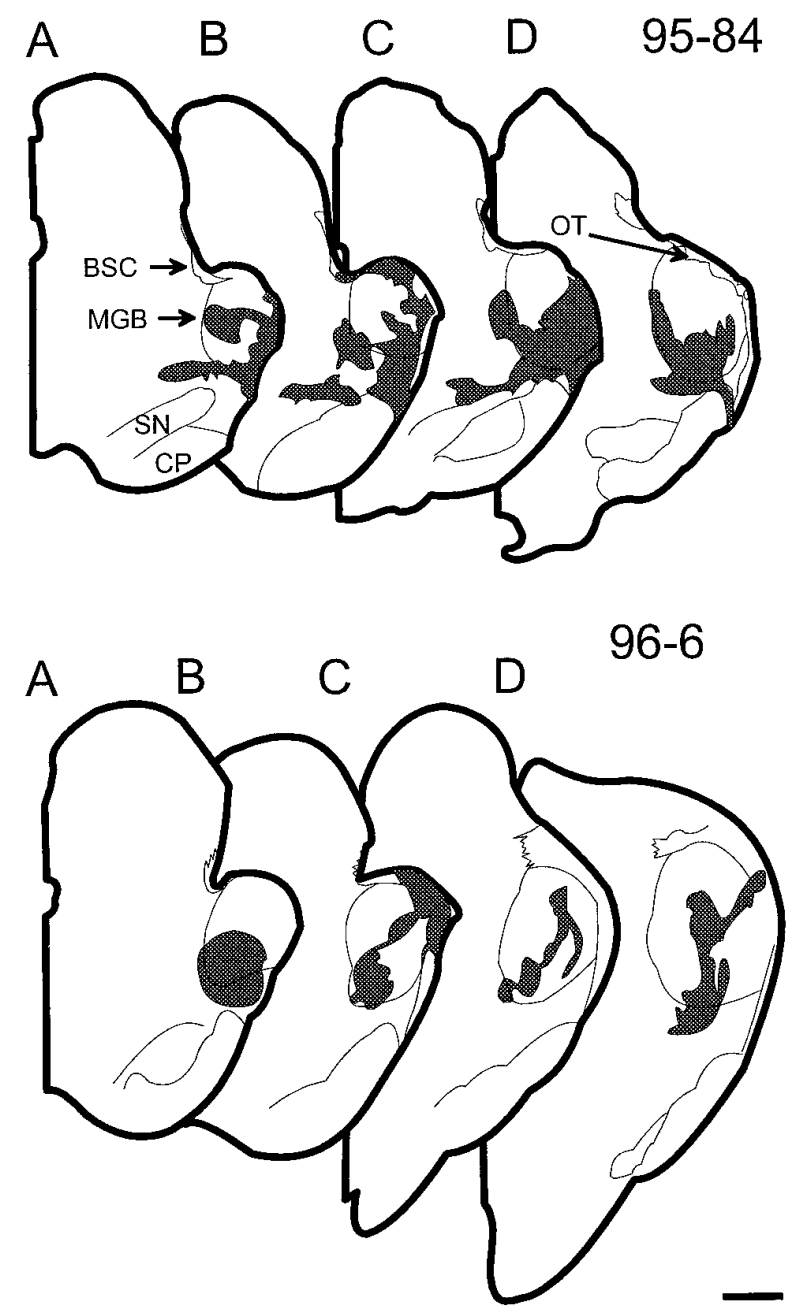

Figure 1. Diagrams of injection sites in the medial geniculate body for two rats. Only half of each transverse section is shown. For each diagram, a section with Nissl cytoarchitecture was overlaid onto an adjacent section processed for immunohistochemistry. All diagrams are made from $50 \mu \mathrm{m}$ sections. The injection site is indicated by the dark area. In 95-84, the total rostro-caudal span is $900 \mu \mathrm{m}$, with each illustrated section separated by $300 \mu \mathrm{m}$. For $96-6$, the total rostro-caudal span is $1750 \mu \mathrm{m}$, with each illustrated section separated by $600 \mu \mathrm{m}$ except in $A$ and $B(550 \mu \mathrm{m}) . M G$, Medial geniculate body; $O T$, optic tract; $B S C$, brachium of the superior colliculus; $S N$, substantia nigra; $C P$, cerebral peduncle. Scale bar, $1 \mathrm{~mm}$.

ance contained within the soma and nucleus, but not within the nucleolus (Fig. 2B). This staining was comparable with that observed in previous studies on the IC in which different antisera were used (Oliver et al., 1994; Winer et al., 1996) and with that seen in cerebellar stellate and basket neurons in the present material (data not shown). The "bead-labeled" neurons had a distinct granular appearance within the cytoplasm that represented the presence of latex microspheres transported from the injection site in the MGB (Fig. 2A, red cell). Microspheres were never located within the nucleus. "Double-labeled" neurons had green FITC signal and red microspheres throughout the soma but only green FITC signal in the nucleus (Fig. $2 A, C, D$ ). Doublelabeled cells were interpreted as GABA-positive projection neurons.

All parts of the auditory pathway in the ipsilateral midbrain were surveyed for GABA-positive, bead-labeled, and double-labeled neurons. Nearly 7500 neurons in four cases were counted. Table 1 shows
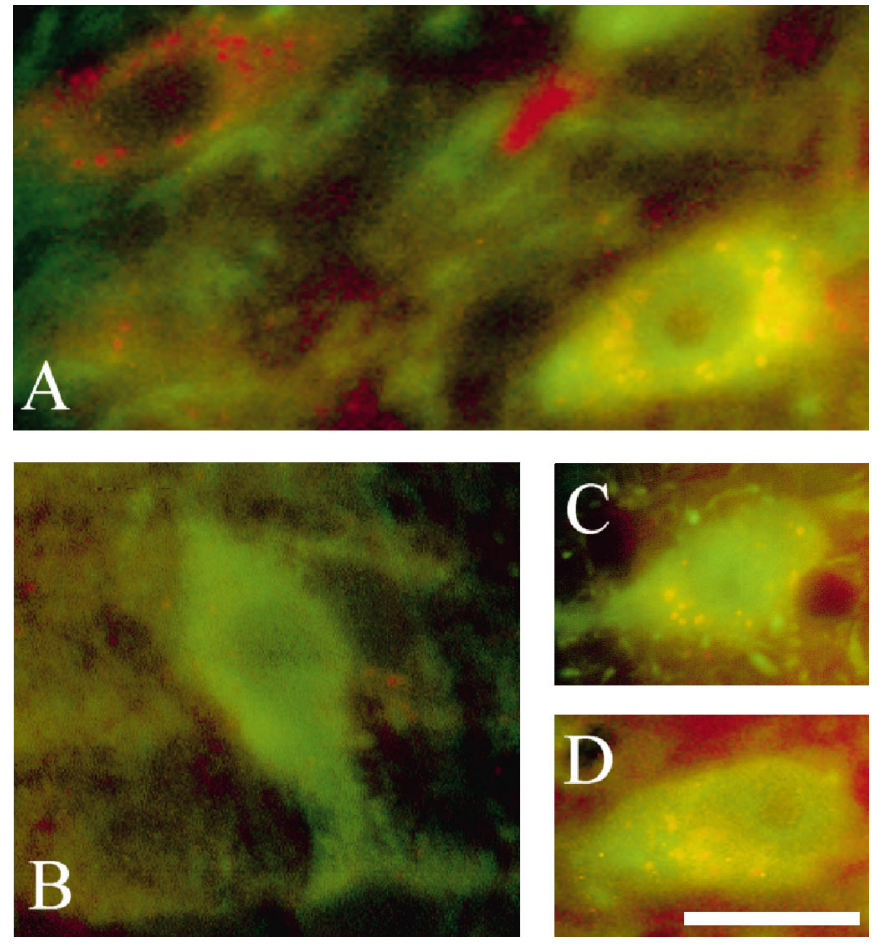

Figure 2. The labels for retrograde transport and GABA-positive immunoreactivity were easily distinguished. GABA-positive immunoreactivity was indicated by FITC label with a uniform green appearance contained within the soma and nucleus but not within the nucleolus $(B)$. The bead-labeled neurons had a distinct granular appearance within the cytoplasm that represented the presence of red latex microspheres $(A$, cell at top left). Microspheres were never located within the nucleus. "Doublelabeled" neurons had green FITC signal and red microspheres throughout the soma but only green FITC signal in the nucleus $(A$, right cell; $C, D)$. These digital video images were made by combining original, monochrome digital video images into a single color RGB image. The microsphere image was assigned to the red band, whereas the FITC image was assigned to the green band. All contrast and brightness adjustments were performed evenly throughout the entire image. Scale bar, $25 \mu \mathrm{m}$.

the number of neurons counted in each area in each case and the ratio of double-labeled neurons to the bead-labeled plus doublelabeled neurons. This percentage represents an estimate of the GABA-positive projection neurons to the MGB.

The central nucleus of the IC had many double-labeled neurons that project to the ipsilateral MGB. The spatial distribution of single- and double-labeled neurons in the IC is seen in Figures 3 and 4 . In these diagrams, double-labeled neurons are shown as solid circles, bead-labeled neurons as open squares, and GABApositive neurons as open triangles. All three cell types were abundant in the central nucleus, and the number of GABApositive projection neurons often appeared greater ventrally (Figs. 3, 4, CN). GABA-immunoreactive neurons, that is, both GABA-positive and double-labeled cells, were more numerous in the ventral half of central nucleus $\left(\sim 63\right.$ cells $/ \mathrm{mm}^{2}$ dorsally and 92 cells $/ \mathrm{mm}^{2}$ ventrally). Likewise, the projection neurons (beadlabeled plus double-labeled cells) also were more numerous ventrally. Approximately 80 projection neurons per $\mathrm{mm}^{2}$ were found in dorsal central nucleus as compared with 108 cells $/ \mathrm{mm}^{2}$ ventrally. The relative higher density of cells probably accounts for the greater density of double-labeled, projection neurons in the ventral central nucleus.

Other IC subdivisions contained double-labeled neurons that 
Table 1. Percentage of retrogradely labeled neurons that are GABA positive

Subdivision and number of cells counted per subdivision

\begin{tabular}{|c|c|c|c|c|c|c|c|c|c|}
\hline & $\begin{array}{l}\mathrm{CN} \\
2876\end{array}$ & $\begin{array}{l}\mathrm{CN}_{\mathrm{D}} \\
1311\end{array}$ & $\begin{array}{l}\mathrm{CN}_{\mathrm{V}} \\
1565\end{array}$ & $\begin{array}{l}\mathrm{DC} \\
1163\end{array}$ & $\begin{array}{l}\text { LC3 } \\
642\end{array}$ & $\begin{array}{l}\text { LC1,2 } \\
818\end{array}$ & $\begin{array}{l}\text { DLL } \\
174\end{array}$ & $\begin{array}{l}\text { nBIC } \\
162\end{array}$ & $\begin{array}{l}\text { TEG } \\
1305\end{array}$ \\
\hline $95-84$ & 38 & 26 & 49 & 14 & 29 & 18 & 69 & 0 & 3 \\
\hline $96-4$ & 48 & 43 & 51 & 23 & 39 & 36 & 50 & 18 & 11 \\
\hline $96-5$ & 57 & 54 & 58 & 28 & 60 & 44 & 75 & 22 & 9 \\
\hline $96-6$ & 38 & 25 & 52 & 16 & 54 & 36 & 80 & 3 & 3 \\
\hline Mean $\pm \mathrm{SE}$ & $45 \pm 3$ & $37 \pm 5$ & $52 \pm 2$ & $20 \pm 3$ & $45 \pm 5$ & $33 \pm 4$ & $69 \pm 7$ & $10 \pm 5$ & $6 \pm 2$ \\
\hline
\end{tabular}

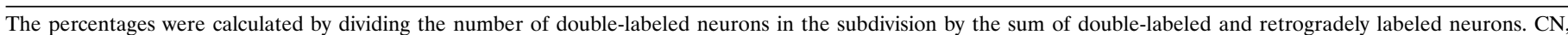

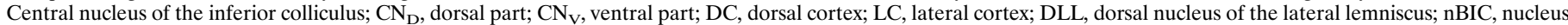
of the brachium of the inferior colliculus; TEG, tegmentum.

project to the ipsilateral MGB. The deepest layer of lateral cortex (Figs. 3, 4, L3) and the interstitial zone of the central nucleus (Figs. 3, 4, IS) had GABA-positive and double-labeled cells in a density similar to that in the central nucleus. These areas had significant numbers of GABA-positive projection neurons, as did the ventrolateral nucleus (Fig. 3,VL). However, in other areas of the IC, there were fewer GABA-containing neurons, whereas many projection neurons were evident. In the dorsal cortex, the density of GABA-positive and double-labeled neurons together was 47 cells $/ \mathrm{mm}^{2}$. Consequently, there were fewer double-labeled neurons in the dorsal cortex compared with the total number of bead-labeled projection neurons. The same was true for the outer two layers of lateral cortex (Figs. 3, 4, L1, L2). Few double-labeled cells were seen in the caudal cortex (Fig. 3A, caudal IC).

The quantitative data from all four cases showed that the central nucleus was the subdivision of the IC that had the highest percentage of GABA-positive projections to the ipsilateral MGB (Table 1). Approximately $45 \%$ of the neurons that project from the central nucleus (Table $1, \mathrm{CN}$ ) to the injection sites were double-labeled. There was a dorsal-ventral difference. The percentage of GABA-positive projection neurons was higher in the ventral central nucleus $(52 \%)$ than in the dorsal central nucleus $(38 \%)$ (Table 1). Percentages of GABA-positive projection neurons similar to those of the central nucleus were found in the deepest layer of lateral cortex (Table 1, LC3). In contrast, the percentage of the GABA-positive tectothalamic projection neurons in the dorsal cortex (Table 1, DC) was $20 \%$ and significantly different from the percentage in the central nucleus and deep lateral cortex. The two outer layers of lateral cortex (Table 1, LC1, LC2) also had fewer GABA-positive projection neurons.

Outside the IC, in other areas of the midbrain tegmentum, few GABA-positive cells were found. The nucleus of the BIC had a very small percentage of GABA-positive projection neurons (Table $1, \mathrm{nBIC}, 10 \%)$. The paucity of inhibitory neurons is evident in Figures $3 D$ and $4 C(n B I C)$. The midbrain reticular formation (Figs. $3 A, C, D, 4 C, R F$ ) and the cuneiform nucleus (Figs. $3 B$, $4 A, B, C U N)$ had the fewest GABA-positive and double-labeled neurons. In these areas, only $6 \%$ of the neurons were GABApositive projection neurons (Table $1, \mathrm{TEG}$ ), a significantly lower percentage than that of any subdivision of the IC. Few GABApositive projection neurons were seen in the superior colliculus (Figs. 3D, 4C). Although these tegmental areas and the superior colliculus had few double-labeled cells, bead-labeled neurons were numerous.

In marked contrast to the midbrain tegmentum, the dorsal nucleus of the lateral lemniscus (DNLL) had numerous GABApositive neurons and double-labeled cells that project to the injection sites (Figs. $3 A, 4 A, B$ ). Most of the neurons appeared to be GABA-positive. Many neurons in the dorsal nucleus are retrogradely labeled after our injections in the ipsilateral MGB. Nearly $70 \%$ of the projection neurons to the ipsilateral MGB were GABA-positive. This is the highest percentage of any area examined in the present study (Table 1, DLL). Despite the high percentage, the absolute number of GABA-positive projection neurons from the central nucleus of the IC to the MGB is much higher than the number of projection neurons from the ipsilateral DNLL. Nearly 20 times more neurons were counted in the central nucleus of the IC than in the DNLL. Thus, unless the axons from DNLL have many collaterals in the MGB, the central nucleus is the most likely source of the large majority of the GABAcontaining afferent axons that project to the ipsilateral MGB.

\section{Physiology of inhibitory inputs to the MGB}

Recordings and intracellular injections were obtained from 32 neurons with the anatomical and physiological characteristics of thalamocortical neurons in the dorsal and ventral divisions of the MGB (Fig. 5). These neurons had a mean resting potential of $-66.2 \pm 4.6 \mathrm{mV}$ (range, -58 to -78 ) and an average input resistance of $59 \pm 18 \mathrm{M} \Omega$ (range, 30-104 M $\Omega$ ). In response to depolarizing current injection, all neurons were able to fire action potentials with a mean amplitude of $65.6 \pm 6.4 \mathrm{mV}$ (range, 48-79 $\mathrm{mV}$ ). Furthermore, all neurons exhibited suprathreshold $\mathrm{Ca}^{2+}$. dependent bursts when the membrane potential was hyperpolarized below -65 to $-70 \mathrm{mV}$, and this same $\mathrm{Ca}^{2+}$ spike could also occur after cessation of a hyperpolarizing current and cause a "rebound burst" that generated $\mathrm{Na}^{+}$action potentials. Similar low-threshold $\mathrm{Ca}^{2+}$ spikes have been noted in numerous studies of thalamic neurons (Jahnsen and Llinas, 1984; Steriade and Llinas, 1988; Hu et al., 1994; Hu, 1995).

Injected cells in MGB had either tufted or stellate morphology (Fig. 5). Tufted neurons were more frequently, but not exclusively, located in the ventral division, and stellate cells were more frequently, but not exclusively, located in the dorsal division. Both types of morphology have been attributed to thalamocortical relay neurons (Clerici and Coleman, 1990; Hu et al., 1994). A camera lucida drawing of each cell type is shown in Figure 5. Tufted neurons have shorter dendrites, more oriented dendritic trees, and more intertwined, clustered dendritic trees than do stellate neurons. No clear differences were noted in the basic physiological features of neurons in different MGB locations. The only clear difference that emerged when neurons were subdivided into those with tufted morphology and those with stellate morphology was that neurons receiving large excitatory IC input all had tufted morphology (4/4 cases). 


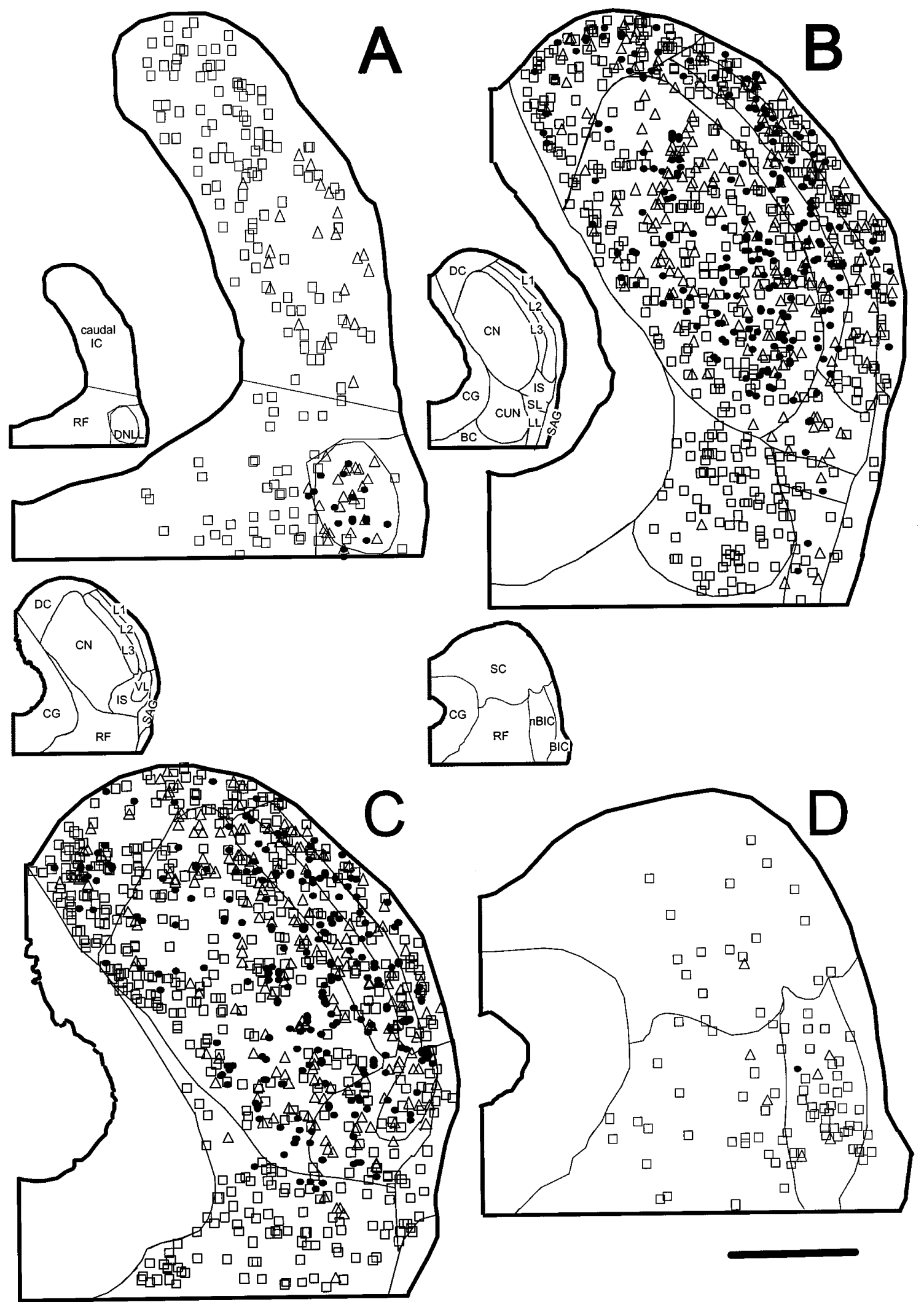

Figure 3. Diagrams of the surveys performed on sections through the caudal midbrain of animal 96-6. A Nissl-stained section has been merged with the fluorescent section on which the cell counting was performed to yield the diagrams shown here. The total rostro-caudal span is $1800 \mu \mathrm{m} ; B$ is $600 \mu \mathrm{m}$ from $A$, $C$ is $300 \mu \mathrm{m}$ from $B$, and $D$ is $900 \mu \mathrm{m}$ from $C$. Open triangles indicate GABA-positive neurons; open squares indicate bead-labeled neurons; solid circles indicate double-labeled neurons. $C N$, Central nucleus; $D C$, dorsal cortex; $L 1, L 2$, and $L 3$, superficial, middle, and deep layers of lateral cortex, respectively; $I S$, interstitial; $S L$, subcollicular; $L L$, lateral lemniscus; $D N L L$, dorsal nucleus of the lateral lemniscus; $C U N$, cuneiform; $R F$, reticular formation; $B I C$, brachium of the inferior colliculus; $n B I C$, nucleus of the brachium of the inferior colliculus; $C G$, central gray; $S C$, superior colliculus. Scale bar, $1 \mathrm{~mm}$. 

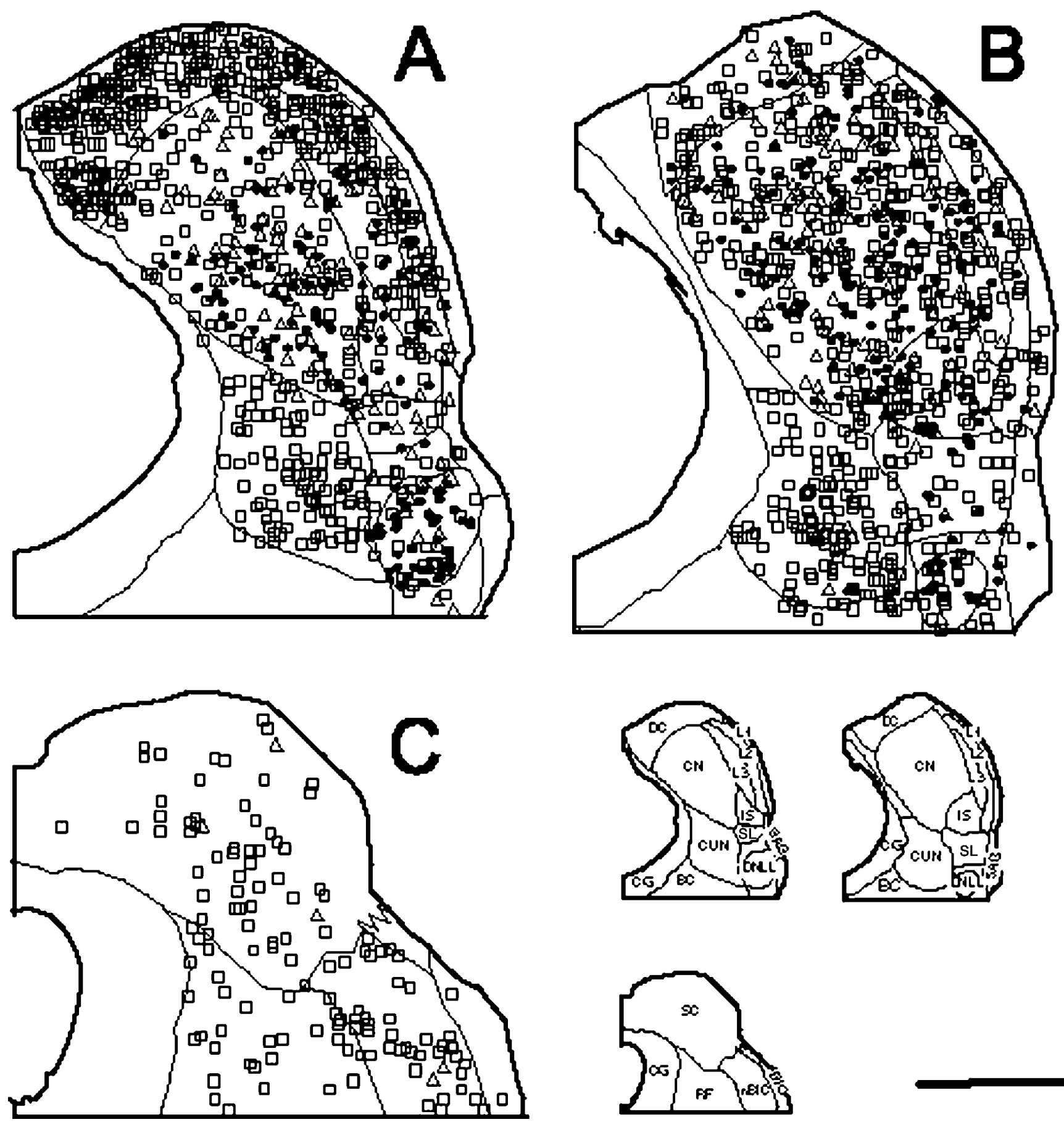

Figure 4. As in Figure 3, diagrams of the surveys done on sections through the caudal midbrain of animal 95-84. The total rostral caudal span is 1500 $\mu \mathrm{m}$ : $B$ is $350 \mu \mathrm{m}$ from $A ; C$ is $1150 \mu \mathrm{m}$ from $B$. See Figure 3 for abbreviations. Scale bar, $1 \mathrm{~mm}$.

Electrical stimulation of the BIC usually generated a shortlatency IPSP in thalamocortical neurons, followed by an EPSP and a second IPSP. In 29 cells, an IPSP was generated by BIC stimulation, whereas in three cells, only an EPSP was generated. In 22 of the 26 neurons with a short-latency IPSP, the response consisted of a short-latency IPSP that preceded a short-latency EPSP, both of which were followed by a long-latency, longduration IPSP. Figure $6 A$ illustrates this response sequence, because the neuron was polarized around its resting potential by current injection. At a resting potential of $-63 \mathrm{mV}$, the shortlatency postsynaptic potential was slightly hyperpolarizing in this cell. As the cell was depolarized away from rest, the postsynaptic potential hyperpolarization became larger. Hyperpolarizing the neuron slightly caused the postsynaptic potential to become depolarizing and suggested that it was an IPSP with a reversal potential near the cell's resting potential.

The reversal potential of the short-latency IPSP was calculated by linear regression for a number of cells that had no EPSP $(n=$ 3 ) or had the EPSPs blocked by the glutamate receptor antagonists APV and DNQX $(n=3)$. Excitatory events were blocked to ensure measurements of the uncontaminated early IPSP amplitude. Figure $6 B$ graphs the peak amplitude of the early IPSP as a 

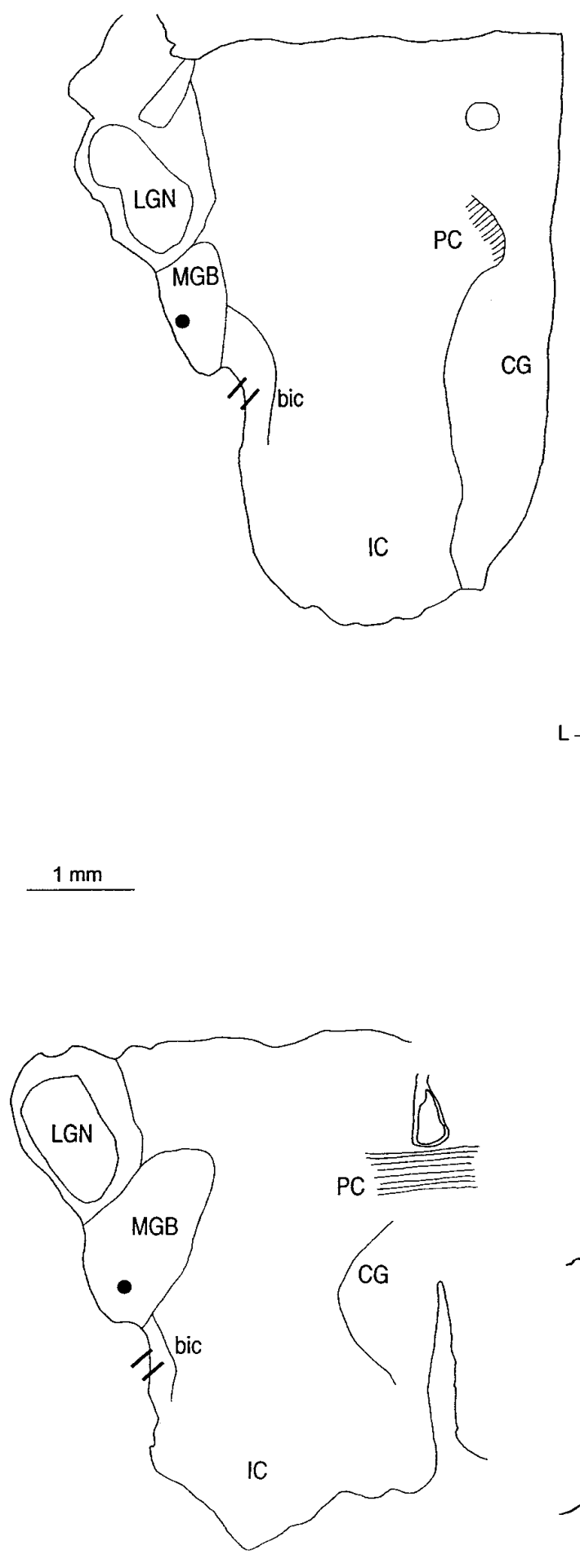

$L-\left.\right|_{C} ^{R} M$
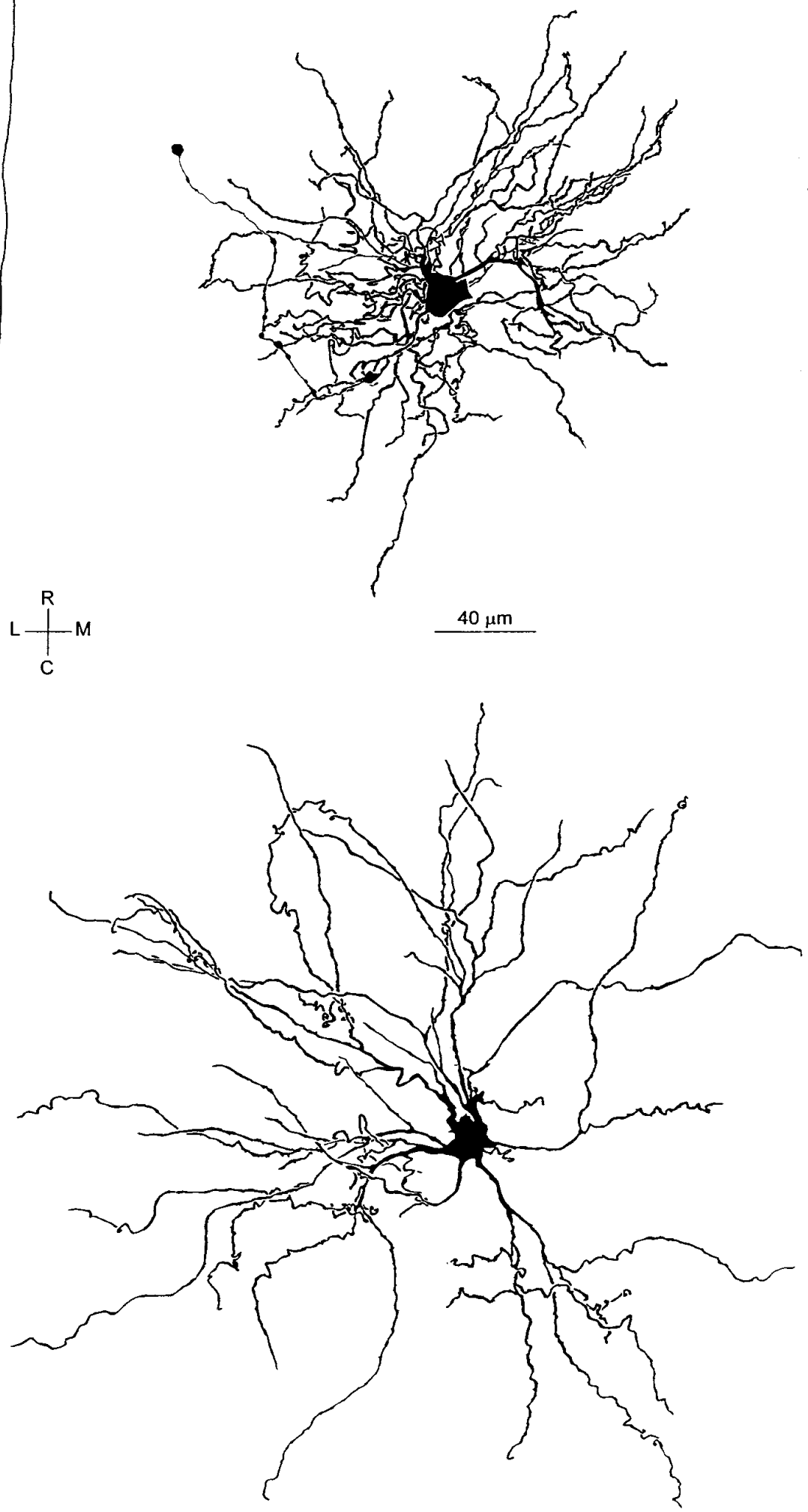

Figure 5. Camera lucida reconstructions of neurobiotin-labeled MGB cells. Top left, Low-power drawing of the horizontal section containing the labeled tufted cell shown on the right. Solid circle in the MGB represents the location of the cell, and the two lines represent the location of the stimulating electrode. Top right, High-power drawing of the labeled tufted cell. Bottom left, Low-power drawing of the horizontal section containing the labeled stellate cell shown on the right. Solid circle represents location of the cell. Bottom right, High-power drawing of the stellate cell. Scale bar on left applies to both low-power drawings; scale bar on right applies to both high-power drawings. bic, Brachium of the inferior colliculus; $C G$, central gray; $L G N$, lateral geniculate nucleus; $M G B$, medial geniculate body; $P C$, posterior commissure. 

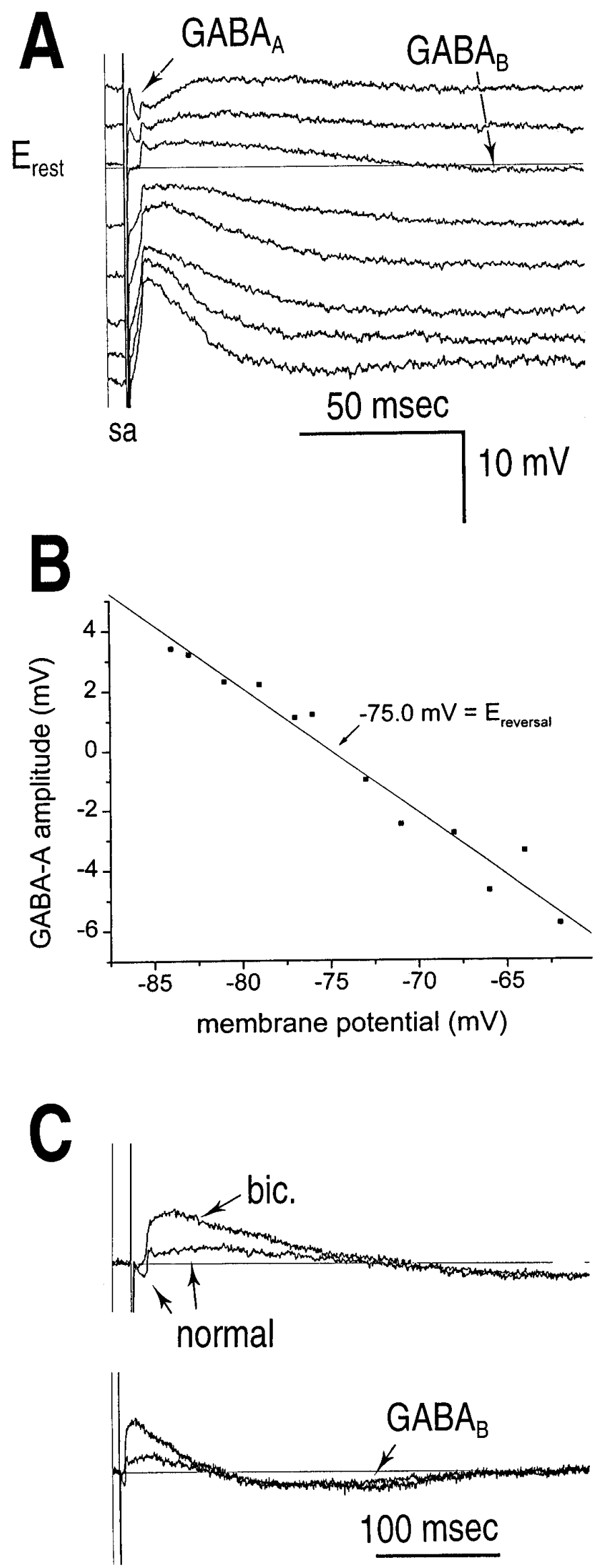

function of the membrane potential recorded during bath perfusion of $50 \mu \mathrm{M} \mathrm{APV}$ and $50 \mu \mathrm{M}$ DNQX. The early IPSP changed linearly with membrane potential and had a reversal potential of $-75.0 \mathrm{mV}$ that is consistent with a chloride-mediated event. In $23 / 26$ of the neurons with an early IPSP, the short latency synaptic event was hyperpolarizing at resting potential.

In all neurons in which polarization of the cell indicated that part of the early synaptic event was inhibitory, the short-latency IPSP was probably mediated by $\mathrm{GABA}_{\mathrm{A}}$ receptors. These IPSPs were consistently blocked by the $\mathrm{GABA}_{\mathrm{A}}$ receptor antagonist bicuculline $(n=3)$. Bath application of $37 \mu \mathrm{M}$ bicuculline abolished the short-latency IPSP, whereas the long-latency IPSP remained (Fig. 6C, bottom trace). Removal of $\mathrm{GABA}_{\mathrm{A}}$ inhibition usually increased the amplitude of the EPSP without changing its latency (Fig. 6C) and could make a subthreshold input suprathreshold (data not shown). GABA $\mathrm{A}$ IPSPs consistently occurred before the EPSP (18/23 cases), with an average latency of $2.0 \pm$ $0.7 \mathrm{msec}$ (range, $1.2-4.1 \mathrm{msec}$ ). The two synaptic events occurred temporally close, because the average latency of the EPSPs was $3.0 \pm 1.5 \mathrm{msec}$ (range, $1.2-6.7 \mathrm{msec}$ ). In most cases $(18 / 23)$, the EPSPs began within 2 msec of IPSP initiation.

A long-latency IPSP mediated by $\mathrm{GABA}_{\mathrm{B}}$ receptors was observed after the short-latency synaptic events in $27 / 29$ neurons. This IPSP was hyperpolarizing at rest in all cases. Figure $7 A$ demonstrates the long-latency response in a multipolar MGB neuron that displayed the typical IPSP/EPSP/IPSP sequence when the cell was polarized around rest. When the amplitude of the late IPSP was plotted versus membrane potential (Fig. 7B), it changed linearly with increasingly depolarized membrane potentials until it was depolarized $>-65 \mathrm{mV}$. The reversal potential of $-84.4 \mathrm{mV}$ is similar to the value obtained for the potassiummediated $\mathrm{GABA}_{\mathrm{B}}$ potentials (Soltesz and Crunelli, 1992). The

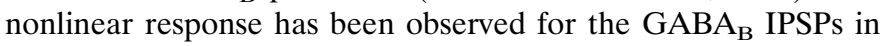
other thalamic areas (Hirsch and Burnod, 1987; Soltesz and Crunelli, 1992). The long-latency IPSP was reduced or eliminated in all cases by the application of the $\mathrm{GABA}_{\mathrm{B}}$ antagonists 2-hydroxysaclofen $(n=4)$ or CGP35348 $(n=1)$. The addition of $250 \mu \mathrm{M}$ of the $\mathrm{GABA}_{\mathrm{B}}$ antagonist 2-hydroxysaclofen blocked the long-latency IPSP (Fig. 7C, sac.), but no changes were seen in the short-latency response (Fig. $7 C$, right column). Although the $\mathrm{GABA}_{\mathrm{B}}$ IPSPs sometimes occurred during the EPSP tail, they

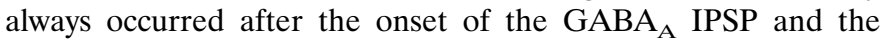
EPSP. GABA ${ }_{B}$ IPSPs had an average latency of $44 \pm 15 \mathrm{msec}$ (range, 16-90 msec) and an average duration of $278 \pm 60 \mathrm{msec}$ (range, 147-370 $\mathrm{msec}$ ).

Figure 6. Early IPSPs are GABAergic and activate $\mathrm{GABA}_{\mathrm{A}}$ receptors. $A$, Shock stimulation of the $B I C$ while polarizing a tufted neuron in the ventral MGB around its resting potential $\left(E_{\text {rest }}=-62.0 \mathrm{mV}\right)$ elicits a short-latency IPSP, followed by a subthreshold EPSP and a subsequent long-latency, long-duration IPSP. $B$, Plot of the amplitude of the $\mathrm{GABA}_{\mathrm{A}}$ component of the IPSP versus membrane potential for another cell with a similar synaptic profile. Measurements were done in the presence of ionotropic glutamate receptor antagonists APV and DNQX to eliminate the EPSP. Regression line through the data indicates a reversal potential of $-75.0 \mathrm{mV}$. C, Superimposed traces showing the response to the same shock strength in normal saline and saline containing $37 \mu \mathrm{M}$ bicuculline (bic.). The cell was slightly depolarized relative to the resting potential in $A$ to more clearly illustrate the early IPSP. The top panel shows that blockade of the early IPSP exposes a large EPSP, whereas the bottom panel (same traces on a longer time scale; time scale in $A$ applies to top trace) illustrates that the later inhibition persists. $s a$, Shock artifact. 
As the intensity of the shock stimulus to the BIC was increased, the relative amplitude of the postsynaptic potentials changed (Fig. $7 C$, top to bottom). The amplitude and duration of the $\mathrm{GABA}_{\mathrm{B}}$ response increased. The $\mathrm{GABA}_{\mathrm{A}}$ response also apparently increased, because the action potentials were eliminated at higher shock intensities. Increasing stimulus intensity presumably drives more afferent axons to MGB neurons; thus, the graded increase in amplitudes with increasing intensities suggests that there are multiple GABAergic synaptic contacts on a single MGB neuron.

Our data indicate that these GABAergic contacts are direct, monosynaptic inputs arising from the axons of the GABA-positive neurons in the IC. To demonstrate the monosynaptic nature of these IPSPs, we added the ionotropic glutamate channel antagonists APV and DNQX to block glutamatergic EPSPs $(n=3)$. Preventing the glutamatergic excitation of interneurons should eliminate interneurons as a source of IPSPs to thalamocortical neurons. Directly stimulated GABAergic axons should be unaffected and still be able produce IPSPs. As shown in Figure $8 A$, the addition of $50 \mu \mathrm{M}$ APV and $50 \mu \mathrm{M}$ DNQX to the bathing solution eliminated the EPSP and revealed more clearly a short-latency IPSP. The long-latency IPSP was also preserved (Fig. $8 B$, same trace as $A$, extended time scale, $G A B A_{\mathrm{B}}$ ) along with the shortlatency IPSP (Fig. $8 B, G A B A_{\mathrm{A}}$ ). This persistence of the IPSPs in the absence of glutamatergic excitation supports the hypothesis that the IPSPs are monosynaptic and arise from axons in the BIC.

\section{DISCUSSION}

We have provided anatomical and physiological evidence that GABAergic neurons from the IC project to the auditory thalamus. GABA-positive projection neurons were most numerous in the central nucleus and less so in the dorsal and lateral cortex. Double-labeled neurons were rare in the lateral tegmental system and BIC. The DNLL contained GABA-positive projection neurons in relatively small numbers. In brain slices of the MGB, GABA-positive projection neurons produced monosynaptic IPSPs in morphologically identified thalamocortical relay neurons. The IPSPs cannot originate locally, because they persisted when glutamatergic transmission was blocked in the MGB. Typically, brachium stimulation elicited a $\mathrm{GABA}_{\mathrm{A}}$-mediated IPSP, followed by an EPSP and longer-latency GABA $_{B}$-mediated IPSP. Shortlatency monosynaptic IPSPs in the thalamus may distinguish the auditory system from other sensory systems.

\section{Sources of the GABAergic inhibition in the MGB}

Local interneurons and thalamic reticular neurons had been thought to be the main sources of GABAergic synapses in the MGB. GABAergic puncta in the rat (Winer and Larue, 1988) and monkey (Smith et al., 1987) were assumed to come from local and reticular thalamic neurons. In the rat, $<1 \%$ of the cell bodies in the MGB were GAD-immunopositive (Winer and Larue, 1988); thus, interneurons appeared to contribute relatively few GABAergic synapses. The present study revealed an alternative source for the GABA-positive input to the MGB.

The IC is probably the main source of ascending inhibition in the rat MGB. GABA-positive neurons are numerous in the IC (Thompson et al., 1985; Roberts and Ribak, 1987; Oliver et al., 1994). In agreement with data from the cat (Winer et al., 1996), we showed that in the rat, the central nucleus, dorsal cortex, and lateral cortex of the IC all contain neurons that express GABA and project to the MGB. The percentage of GABA projection neurons in the central nucleus differs between rat and cat. The rat central nucleus contained more GABA pro- jection neurons than the dorsal cortex (45 vs 20\%). In the cat, the central nucleus had fewer GABA projection neurons $(20 \%)$ than the dorsal cortex $(28 \%)$.

We also found that the ipsilateral DNLL may contribute GABAergic synapses to the MGB. Previous reports (Whitley and Henkel, 1984; Bajo et al., 1993) indicate that the target of this input is the medial division of the MGB. Our intracellular recordings were only from cells in dorsal and ventral MGB; thus, it is unlikely that the shock-evoked IPSPs arose from DNLL.

In contrast to the IC, most of the lateral tegmental projections to the MGB do not appear to provide GABAergic inputs. In the nucleus of the BIC, the percentage of projection neurons with GABA-positive immunoreactivity was small. The weak projection to the dorsal MGB and the absence of a projection to the ventral MGB (Kudo et al., 1984) make the nucleus of the brachium an unlikely source of our observed inhibitory synaptic events. The reticular formation (including the cuneiform nucleus) also had projection neurons to the MGB; however, the vast majority of the projection neurons did not contain GABA. These areas were identified as the lateral tegmental system (Morest, 1965; Henkel, 1983 ) in the cat. It appears that this system does not have a GABAergic component in the rat.

The GABA-positive projection neurons in the IC are likely to release GABA, activate GABA receptors, and produce the IPSPs observed in MGB neurons. When the axons of the BIC were shocked, IPSPs were elicited in the MGB neurons identified morphologically as thalamocortical neurons. The IPSPs were deemed monosynaptic based on their continued presence during blockade of ionotropic glutamate receptors. This blockade strongly supports the argument that the IPSPs arise from outside the thalamus. Blocking glutamate receptors eliminates excitatory inputs to MGB interneurons and the indirect excitation of thalamic reticular neurons that are additional sources of polysynaptic inhibition. The IPSPs in the MGB neurons were blocked with bicuculline, a $\mathrm{GABA}_{\mathrm{A}}$ receptor antagonist, and by 2-hydroxysaclofen and CGP35348, GABA B $_{\mathrm{B}}$ antagonists. This blockade suggests that GABA was present in the synapses made by some tectothalamic axons and shows that GABA was acting on $\mathrm{GABA}_{\mathrm{A}}$ and $\mathrm{GABA}_{\mathrm{B}}$ receptors. GABA-mediated IPSPs also have been observed in other in vitro studies of the rat MGB after stimulation of the BIC (Hu, 1993, 1995; Hu et al., 1994). However, the previous studies did not investigate the sources of the IPSPs in the MGB or the neurotransmitters used.

\section{Patterns of inhibitory and excitatory potentials in the MGB and other thalamic nuclei}

The present study showed a distinct pattern of synaptic potentials in rat MGB resulting from stimulation of the BIC. In most cases, the $\mathrm{GABA}_{\mathrm{A}}$-mediated IPSP arrived before the EPSP. Although there was overlap in EPSP and IPSP latencies, almost all neurons were first inhibited, then excited. Both of these early postsynaptic events were followed by a longer-lasting $\mathrm{GABA}_{\mathrm{B}}$-mediated IPSP. This pattern of synaptic potentials had not been reported previously, although in one study, brachium stimulation evoked IPSPs in the ventral MGB, and in one of their figures, the initial IPSP appears to occur before the EPSP (Hu, 1995, his Fig. 8A).

In the lateral geniculate body, there is little evidence for an ascending, monosynaptic, inhibitory input that precedes excitation to thalamocortical neurons from retinal (Lugo-Garcia and Blanco, 1991; Pow et al., 1994) or nonretinal (Cucchiaro et al., 1991) sources. In brain slices of the rat lateral geniculate body, optic tract stimulation resulted in IPSPs that followed EPSPs (Hirsch and Burnod, 1987; Crunelli et al., 1988). These IPSPs were attributed to local 

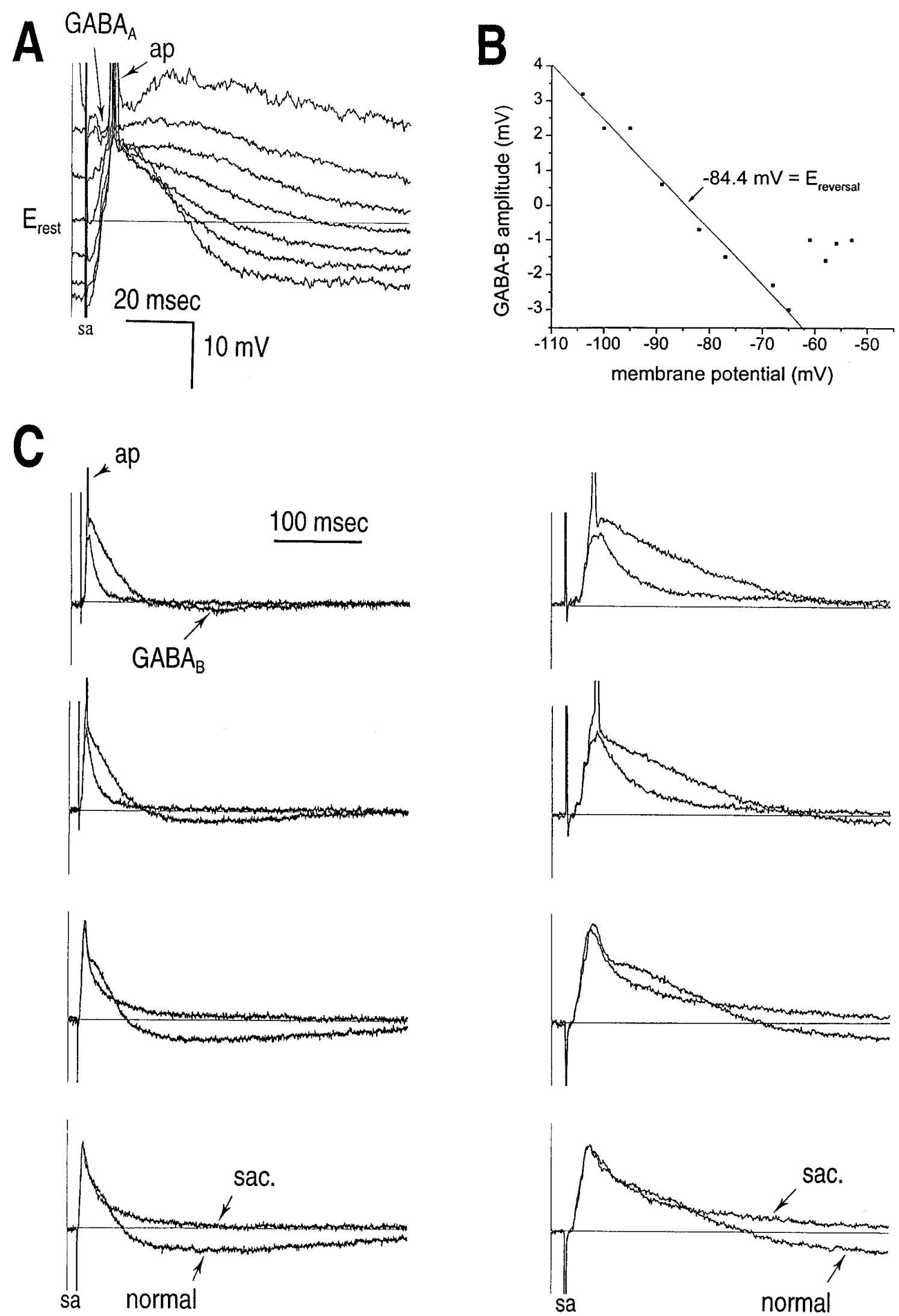

Figure 7. Late IPSPs are GABAergic and activate $\mathrm{GABA}_{\mathrm{B}}$ receptors. $A$, Shock stimulation of the BIC while polarizing a stellate cell in the dorsal MGB around its resting potential $\left(E_{\text {rest }}=-67 \mathrm{mV}\right)$ elicits a short-latency IPSP $\left(\mathrm{GABA}_{\mathrm{A}}\right)$ and a subsequent suprathreshold EPSP $(a p)$, followed by a long-latency IPSP. $B$, Plot of the amplitude of the $\mathrm{GABA}_{\mathrm{B}}$ component of the IPSP versus membrane potential for a different neuron. Measurements were done in the presence of ionotropic glutamate receptor antagonists APV and DNQX to eliminate the EPSP. Regression line (Figure legend continues) 


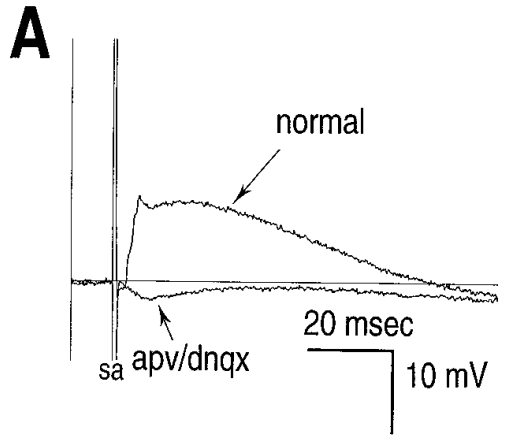

interneurons, because the reticular nucleus of the thalamus was not present in the slice. Furthermore, the IPSPs were more affected than the EPSPs when synaptic transmission was blocked with low calcium. This led the authors to conclude that the IPSPs were polysynaptic (Crunelli et al., 1988). A similar finding was obtained when recording from neurons of the dorsal lateral geniculate body in pentobarbital anesthetized cats (Bloomfield and Sherman, 1988; Lindstrom and Wrobel, 1990).

Evidence is also lacking in the somatosensory thalamus for an ascending GABAergic input that precedes excitation in thalamocortical neurons in the rat (Barbaresi et al., 1986; De Biasi and Rustioni, 1990) and the macaque (Ralston and Ralston, 1994). In vivo intracellular recordings in the ventrobasal thalamus of the rat showed that evoked EPSPs arrived before IPSPs (Salt and Eaton, 1990). These IPSPs are presumed to come from the reticular nucleus of the thalamus, because very few GABAergic neurons are present in the ventrobasal thalamus of the rat (Harris and Hendrickson, 1987).

The thalamic nuclei of the motor system may share certain features of the ascending GABAergic pathway to the MGB. A mixture of excitatory and inhibitory afferent projections converges in the thalamic nuclei that project to motor cortex. These nuclei receive GABAergic, monosynaptic inputs from the globus pallidus and substantia nigra (Chevalier and Deniau, 1990; Parent and Hazrati, 1995). Excitatory input is provided by projections of the deep cerebellar nuclei. Although the motor thalamus receives extrinsic monosynaptic excitation and inhibition, it differs from the organization of the auditory thalamus, because the excitatory and inhibitory projections that we describe originate from the same nucleus. An interplay of extrinsic inhibitory and excitatory input seems to underlie the temporal responses of thalamic motor nuclei. In particular, the inhibition from pallido- and nigrothalamic sources must be removed before neurons in thalamic motor nuclei can be activated.

\section{Functional significance of ascending inhibition to the MGB}

The monosynaptic, GABAergic ascending projections may reflect one aspect of fundamentally different, parallel ascending pathways from the auditory midbrain to the thalamus. Projections ascend from the IC and lateral tegmental system to the MGB
(Morest, 1965; Oliver and Hall, 1978; Calford and Aitkin, 1983; LeDoux et al., 1985). The IC pathway is a progression of the main, tonotopically organized "lemniscal" auditory pathway. On the other hand, the tegmental midbrain projections are less closely related to lateral lemniscal inputs, less tonotopic, and less likely to reflect pure auditory processing in the lower brainstem. The present data now suggest an additional difference in these pathways. The projection from the central nucleus and cortex of the IC may provide strong inhibitory, GABAergic inputs to the MGB. In contrast, the lateral tegmental system may contribute the least GABAergic input; little is known of the neurotransmitters used by these inputs.

Why would the main "lemniscal" auditory pathway to the MGB require a short-latency, monosynaptic, inhibitory input? The unique function of such a direct, ascending inhibitory input may be linked to its ability to perform operations that cannot be accomplished easily by interneurons. As shown by our intracellular recordings, inhibition may occur in MGB neurons before or concurrent with excitation, before GABAergic interneurons would be activated. Although the sequence of postsynaptic potentials in the MGB of a living animal is unknown, acoustic stimuli also may evoke an IPSP/EPSP synaptic response in vivo and inhibit thalamocortical neurons before excitation. One important feature that may be influenced by preceding inhibition is the accuracy of the timing of EPSP-evoked spikes. Our preliminary observations suggest that the ascending inhibition may reduce the jitter in the latency of a synaptically evoked first spike in MGB neurons (E. Bartlett and P. Smith, unpublished observations). Many MGB neurons in anesthetized (Aitkin and Webster, 1972; Rouiller et al., 1983) and unanesthetized animals (Aitkin and Prain, 1974; Allon et al., 1981) show a transient onset response to acoustic stimulation. The ascending monosynaptic inhibition in the MGB may yield a precise control of the latency of such a transient onset response in vivo.

\section{REFERENCES}

Aghajanian GK, Rasmussen K (1989) Intracellular studies in the facial nucleus illustrating a simple new method for obtaining viable motor neurons in adult rat brain slices. Synapse 3:331-338.

Aitkin LM, Prain SM (1974) Medial geniculate body: unit responses in the awake cat. J Neurophysiol 37:512-521.

through the linear portion of the data indicates a reversal potential of $-84.4 \mathrm{mV}$. C, Left column, Superimposed traces of BIC activated synaptic activity to the same shocks in normal saline and saline containing $250 \mu \mathrm{M}$ 2-Hydroxysaclofen from lower (top pair) to higher (bottom pair) shock strengths. As shock strength is increased in normal saline, a late IPSP $\left(\mathrm{GABA}_{\mathrm{B}}\right)$ becomes larger and more pronounced. This component is specifically blocked by the antagonist. Right column, Same traces as seen in the left column at a different time scale to illustrate the apparent lack of effect of the GABA $\mathrm{B}_{\mathrm{B}}$ antagonist

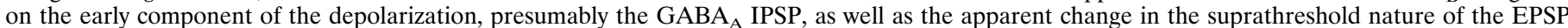
at low shock strengths. Time scale bar in $A$ applies to all traces in $A$ and the right column in $C$. Time scale bar in $B$ applies to traces in the left column. Voltage scale bar in $A$ applies to all traces. ap, Action potential; sac., saclofen; sa, shock artifact. 
Aitkin LM, Webster WR (1972) Medial geniculate body of the cat: organization and responses to tonal stimuli of neurons in the ventral division. J Neurophysiol 35:365-380.

Allon N, Yeshurun Y, Wollberg Z (1981) Responses of single cells in the medial geniculate body of awake squirrel monkeys. Exp Brain Res 41:222-232.

Bajo VM, Merchan MA, Lopez DE, Rouiller EM (1993) Neuronal morphology and efferent projections of the dorsal nucleus of the lateral lemniscus in the rat. J Comp Neurol 334:241-262.

Barbaresi P, Spreafico R, Frassoni C, Rustioni A (1986) GABAergic neurons are present in the dorsal column nuclei but not in the ventroposterior complex of rats. Brain Res 382:305-326.

Bloomfield SA, Sherman SM (1988) Postsynaptic potentials recorded in neurons of the cat's lateral geniculate nucleus following electrical stimulation of the optic chiasm. J Neurophysiol 60:1924-1945.

Calford MB, Aitkin LM (1983) Ascending projections to the medial geniculate body of the cat: evidence for multiple, parallel auditory pathways through thalamus. J Neurosci 3:2365-2380.

Chevalier G, Deniau JM (1990) Disinhibition as a basic process in the expression of striatal functions. Trends Neurosci [Review] 13:277-280.

Clerici WJ, Coleman JR (1990) Anatomy of the rat medial geniculate body. I. Cytoarchitecture, myeloarchitecture, and neocortical connectivity. J Comp Neurol 297:14-31.

Crunelli V, Haby M, Jassik-Gerschenfeld D, Leresche N, Pirchio M (1988) $\mathrm{Cl}^{-}$- and $\mathrm{K}^{+}$-dependent inhibitory postsynaptic potentials evoked by interneurones of the rat lateral geniculate nucleus. J Neurophysiol 399:153-176.

Cucchiaro JB, Bickford ME, Sherman SM (1991) A GABAergic projection from the pretectum to the dorsal lateral geniculate nucleus in the cat. Neuroscience 41:213-226.

De Biasi S, Rustioni A (1990) Ultrastructural immunocytochemical localization of excitatory amino acids in the somatosensory system. J Histochem Cytochem 38:1745-1754.

Harris RM, Hendrickson AE (1987) Local circuit neurons in the rat ventrobasal thalamus-a GABA immunocytochemical study. Neuroscience 21:229-236.

Henkel CK (1983) Evidence of sub-collicular auditory projections to the medial geniculate nucleus in the cat: an autoradiographic and horseradish peroxidase study. Brain Res 259:21-30.

Hirsch JC, Burnod Y (1987) A synaptically evoked late hyperpolarization in the rat dorsolateral geniculate neurons in vitro. Neuroscience 23:457-468.

$\mathrm{Hu}$ B (1993) Membrane potential oscillations and corticothalamic connectivity in rat associational thalamic neurons in vitro. Acta Physiol Scand 148:109-113.

Hu B (1995) Cellular basis of temporal synaptic signalling: an in vitro electrophysiological study in rat auditory thalamus. J Physiol (Lond) 483:167-182.

Hu B, Senatorov V, Mooney D (1994) Lemniscal and non-lemniscal synaptic transmission in rat auditory thalamus. J Physiol (Lond) 479:217-231.

Jahnsen H, Llinas R (1984) Electrophysiological properties of guinea-pig thalamic neurones: an in vitro study. J Physiol (Lond) 349:205-226.

Kudo M, Tashiro T, Higo S, Matsuyama T, Kawamura S (1984) Ascending projections from the nucleus of the brachium of the inferior colliculus in the cat. Exp Brain Res 54:203-211.

LeDoux JE, Ruggiero DA, Reis DJ (1985) Projections to the subcortical forebrain from anatomically defined regions of the medial geniculate body in the rat. J Comp Neurol 242:182-213.

Lindstrom S, Wrobel A (1990) Private inhibitory systems for the X and Y pathways in the dorsal lateral geniculate nucleus of the cat. J Neurophysiol 429:259-280.

Lugo-Garcia N, Blanco RE (1991) Localization of GAD- and GABAlike immunoreactivity in ground squirrel retina: retrograde labeling demonstrates GAD-positive ganglion cells. Brain Res 564:19-26.
Morest DK (1965) The lateral tegmental system of the midbrain and the medial geniculate body: study with Golgi and Nauta methods in cat. J Anat 99:611-634.

Oliver DL, Hall WC (1978) The medial geniculate body of the tree shrew, Tupaia glis. II. Connections with the neocortex. J Comp Neurol 182:459-494.

Oliver DL, Winer JA, Beckius GE, Saint MRL (1994) Morphology of GABAergic neurons in the inferior colliculus of the cat. J Comp Neurol 340:27-42.

Pape HC, McCormick DA (1995) Electrophysiological and pharmacological properties of interneurons in the cat dorsal lateral geniculate nucleus. Neuroscience 68:1105-1125.

Parent A, Hazrati LN (1995) Functional anatomy of the basal ganglia. I. The cortico-basal ganglia-thalamo-cortical loop. Brain Res [Review] 20:91-127.

Paxinos G, Watson C (1986) The rat brain in stereotaxic coordinates. Ed 2. San Diego: Academic.

Pow DV, Crook DK, Wong RO (1994) Early appearance and transient expression of putative amino acid neurotransmitters and related molecules in the developing rabbit retina: an immunocytochemical study. Vis Neurosci 11:1115-1134.

Ralston III HJ, Ralston DD (1994) Medial lemniscal and spinal projections to the macaque thalamus: an electron microscopic study of differing GABAergic circuitry serving thalamic somatosensory mechanisms. J Neurosci 14:2485-2502.

Roberts RC, Ribak CE (1987) An electron microscopic study of GABAergic neurons and terminals in the central nucleus of the inferior colliculus of the rat. J Neurocytol 16:333-345.

Rouiller E, de Ribaupierre Y, Morel A, de Ribaupierre F (1983) Intensity functions of single unit responses to tone in the medial geniculate body of cat. Hear Res 11:235-247.

Salt TE, Eaton SA (1990) Postsynaptic potentials evoked in ventrobasal thalamus neurones by natural sensory stimuli. Neurosci Lett 114:295-299.

Sherman SM, Koch C (1986) The control of retinogeniculate transmission in the mammalian lateral geniculate nucleus. Exp Brain Res [Review] 63:1-20.

Smith PH (1992) Anatomy and physiology of multipolar cells in the rat inferior collicular cortex using the in vitro brain slice technique. J Neurosci 12:3700-3715.

Smith Y, Seguela P, Parent A (1987) Distribution of GABAimmunoreactive neurons in the thalamus of the squirrel monkey (Saimiri sciureus). Neuroscience 22:579-591.

Soltesz I, Crunelli V (1992) GABA $_{\mathrm{A}}$ and pre- and post-synaptic $\mathrm{GABA}_{\mathrm{B}}$ receptor-mediated responses in the lateral geniculate nucleus. Prog Brain Res 90:151-169.

Steriade M, Llinas RR (1988) The functional states of the thalamus and the associated neuronal interplay. Physiol Rev [Review] 68:649-742.

Thompson GC, Cortez AM, Lam DM (1985) Localization of GABA immunoreactivity in the auditory brainstem of guinea pigs. Brain Res 339:119-122.

Whitley JM, Henkel CK (1984) Topographical organization of the inferior collicular projection and other connections of the ventral nucleus of the lateral lemniscus. J Comp Neurol 229:257-270.

Winer JA, Larue DT (1988) Anatomy of glutamic acid decarboxylase immunoreactive neurons and axons in the rat medial geniculate body. [Published erratum appears in J Comp Neurol, 1989, 280:499-500.rsqb]. J Comp Neurol 278:47-68.

Winer JA, Larue DT (1996) Evolution of GABAergic circuitry in the mammalian medial geniculate body. Proc Natl Acad Sci USA 93:3083-3087.

Winer JA, Saint Marie RL, Larue DT, Oliver DL (1996) GABAergic feedforward projections from the inferior colliculus to the medial geniculate body. Proc Natl Acad Sci USA 93:8005-8010. 